\title{
ASESMEN KOMPETENSI MINIMUM DAN SURVEI KARAKTER DI INDONESIA SERTA RELEVANSINYA DENGAN PEMIKIRAN IBNU SINA
}

\section{MINIMUM COMPETENCY ASSESSMENT AND CHARACTER SURVEY IN INDONESIA AND ITS RELEVANCE TO IBNU SINA THOUGHTS}

\author{
Dewi Ratna Sari \\ Universitas Ahmad Dahlan, Yogyakarta, Indonesia \\ Email: dewi1908052020@webmail.uad.ac.id \\ Betty Mauli Rosa \\ Universitas Ahmad Dahlan, Yogyakarta, Indonesia \\ Email: betty.rosa@bsa.uad.ac.id
}

\begin{abstract}
Abstrak
Nadiem Makarim selaku Menteri Pendidikan dan Kebudayaan RI memaparkan gagasannya tentang \#MerdekaBelajar. Salah satu poinnya adalah penggantian Ujian Sekolah Standar Nasional (USBN) menjadi Penilaian Kompetensi Minimum dan Survei Karakter. Ada tiga komponen yang dinilai yaitu: literasi, numerasi dan karakter. Konsep ini perlu digali dengan mengaitkannya dengan konsep-konsep pendidikan yang sudah ada sebelumnya agar dapat dinilai konsep dan praksisnya. Melalui penelitian kualitatif studi pustaka menunjukkan konsep \#Merdeka Belajar sangat sesuai dengan pandangan Ibnu Sina tentang pendidikan. Ibnu Sina dalam tulisan dan konsepnya juga menekankan pentingnya membaca, matematika dan ilmu pengetahuan serta akhlak yang mulia. Konsep \#MerdekaBelajar dan pemikiran Ibnu Sina selaras dan saling melengkapi. Meskipun ada perbedaan pentingnya pengembangan aspek fisik yang belum dibahas dalam Penilaian Kompetensi Minimum dan Survei Karakter di Indonesia.
\end{abstract}

Kata Kunci: pendidikan, \#MerdekaBelajar, konsep

\begin{abstract}
Nadiem Makarim as Minister of Education and Culture of Indonesia explained his ideas about \#MerdekaBelajar. One of the points is the replacement of the National Standard School Examination (USBN) into a Minimum Competency Assessment and Character Survey. There are three components which are assessed namely literacy, numeracy and character. This concept needs to be explored by linking it with preexisting education concepts in order to be assessed about their conceptual and praxis. Through qualitative research library research shows the concept of \#Merdeka Belajar is very consistent with Ibn Sina's view of education. Ibn Sina in his writings and concepts also emphasizes the importance of reading, mathematics and science and noble morals. The concept of \#MerdekaBelajar and Ibn Sina's thinking in harmony and complementary. Although there are differences in the importance of developing physical aspects that have not been discussed in the Minimum Competency Assessment and Character Survey in Indonesia.
\end{abstract}

Keywords: education, \#MerdekaBelajar, concept 
Dewi Ratna Sari \& Betty Mauli Rosa: Asesmen Kompetensi Minimum dan Survey Karakter di Indonesia serta Relevansinya dengan Pemikiran Ibnu Sina

\section{A. Pendahuluan}

\#MerdekaBelajar adalah gagasan yang ditawarkan oleh Menteri Pendidikan dan Kebudayaan (Mendikbud) Nadiem Makarim. Ada empat pokok kebijakan pendidikan yang dibahas meliputi: 1) Ujian Sekolah Berstandar Nasional (USBN). 2) Ujian Nasional (UN). 3) Rencana Pelaksanaan Pembelajaran (RPP). 4) Peraturan Penerimaan Peserta Didik Baru (PPDB) Zonasi. Keempat kebijakan tersebut merupakan sebuah upaya yang dilakukan oleh pemangku kebijakan di bidang pendidikan guna menghadapi perkembangan yang ada.

Mengenai konsep Ujian Sekolah Berstandar Nasional (USBN) dan Ujian Nasional (UN) dalam \#MerdekaBelajar tahun 2020 direncanakan sebagai tahun terakhir. Pada 2021 UN dihapuskan diubah menjadi Asesmen Kompetensi Minimum dan Survei Karakter. ${ }^{1}$ Namun karena adanya Covid-19 pelaksanaan USBN pada tahun 2020 akhirnya juga ditiadakan. Menurut Nadiem Makarim, Asesmen Kompetensi Minimum dan Survei Karakter terdiri dari kemampuan bernalar menggunakan bahasa (literasi), kemampuan bernalar menggunakan matematika (numerasi) dan penguatan pendidikan karakter. $^{2}$

Lebih dari itu menurut Jihad Ahmad Muta'ali dalam tulisannya yang berjudul “Opini Masyarakat tentang Asesmen Nasional sebagai Pengganti Ujian Nasional” menjelaskan bahwa dari hasil angket didapatkan hasil sebesar 91,9\% masyarakat awam maupun masyarakat intelektual setuju adanya penggantian Ujian Nasional yang kan diganti dengan Asesmen Nasional pada tahun 2021. Asessmen ini mempertimbangkan penilaian yang didasarkan atas kemampuan peserta didik dalam kognitif, tidak hanya membaca namun juga memotivasi siswa ntuk menganalisis simbol-simbol angka dan dipraktikkan dalam kehidupan sehari-hari. ${ }^{3}$

Ketika membahas mengenai konsep Asesmen Kompetensi Minimum dan Survei Karakter dalam \#MerdekaBelajar perlu kiranya kita menarik mundur dan menelaahnya dengan konsep pendidikan yang dikemukakan oleh tokoh pendidikan di masa

\footnotetext{
${ }^{1}$ Yudono Yanuar, "Inilah Asesmen Kompetensi Minimum Pengganti Ujian Nasional,” tempo.co, 2019, https://tekno.tempo.co/read/1284119/inilah-asesmen-kompetensi-minimum-pengganti-ujiannasional/full\&view $=$ ok.

${ }^{2}$ Wahyu Adityo Prodjo, "Mendikbud Nadiem Hapus UN Lewat Merdeka Belajar, Ini Penggantinya," kompas.com, 2019, https://edukasi.kompas.com/read/2019/12/11/13264851/mendikbudnadiem-hapus-un-lewat-merdeka-belajar-ini-penggantinya.

${ }^{3}$ Jihad Ahmad Muta'ali, "Opini Masyarakat tentang Asesmen Nasional sebagai Penganti Ujian Nasional," Journal of Chemical Information and Modeling, Vol. 53, No. 9 (2020): 1689-99.
} 
sebelumnya. Hal tersebut bertujuan agar kita mengetahui secara lebih luas dari aspek filosofis, konseptual maupun prosedural mengenai relevansi \#MerdekaBelajar dengan konsep pendidikan yang telah ada sebelumnya.

Pemikiran pendidikan menurut Ibnu Sina adalah salah satu konsep pendidikan yang bisa dijadikan sebagai pembanding. Melalui pengalaman dan kontribusinya yang besar dalam peradaban Islam, membuat gagasan Ibnu Sina tentang pendidikan menjadi patut untuk diperhatikan. Salah satu konsep pemikiran tokoh yang di Barat dikenal sebagai Avicenna ini adalah menilai pendidikan tidak hanya mengenai pentingnya akal, tetapi juga berkelindan dengan perlunya memanfaatkan potensi mengenai hati dan gerak/skill. Hal tersebut karena tujuan pendidikan sangat berkelindan dengan pengembangan manusia paripurna atau insan kamil. Ibnu Sina juga merupakan tokoh yang telah membahas mengenai pentingnya literasi, numerasi dan penguatan karakter dalam pendidikan melalui kurikulum dan konsep pendidikannya. Tiga hal yang menjadi komponen utama dalam pembahasan pergantian Ujian Akhir Sekolah Berbasis Nasional (UASBN) di era \#MerdekaBelajar.

Penelitian mengenai Asesmen Kompetensi Minimum dan Survei Karakter di Indonesia serta relevansinya dengan pemikiran Ibnu Sina menjadi penting untuk dilakukan di masa sekarang. Dengan mengurai relevansi antara \#MerdekaBelajar dengan pemikiran Ibnu Sina kita bisa melihat konsep \#MerdekaBelajar ini dengan lebih utuh sekaligus menilainya apakah sesuai dengan konsep ideal mengenai pendidikan atau tidak.

\section{B. Metode}

\section{Jenis Penelitian}

Penelitian ini menggunakan pendekatan kualitatif studi pustaka (library research) untuk menelaah konsep Asesmen Kompetensi Minimum dan Survei Karakter dalam \#Merdeka Belajar dan pemikiran pendidikan menurut Ibnu Sina.

\section{Prosedur}

Penelitian ini menggunakan pendekatan kualitatif studi pustaka (library research) yang menganalisis pemikiran Ibnu Sina dan gagasan \#MerdekaBelajar. Peneliti menggunakan sumber rujukan berupa jurnal, buku, undang-undang maupun 
Dewi Ratna Sari \& Betty Mauli Rosa: Asesmen Kompetensi Minimum dan Survey Karakter di Indonesia serta Relevansinya dengan Pemikiran Ibnu Sina

sumber referensi terkait dua hal tersebut. Adapun metode analisis data menggunakan model Miles dan Huberman yang memuat reduksi data, penyajian data dan verifikasi.

\section{Data, Intrumen, dan Teknik Pengumpulan Data}

Peneliti menggunakan sumber rujukan berupa jurnal, buku, undang-undang maupun sumber referensi Asesmen Kompetensi Minimal dan Survei Karakter dalam \#MerdekaBelajar dan pemikiran pendidikan menurut Ibnu Sina. Peneliti menelaah tulisan tentang Ibnu Sina seperti karya: Ummu Kulsum tentang Implementasi Pendidikan Akhlak untuk Membentuk Karakter Siswa dalam Perspektif Ibnu Sina dan Mukhtar Gozali tentang Agama dan Filsafat dalam Pemikiran Ibnu Sina. Yang menjadi pembeda, penulis turut menghubungkannya dengan kebijakan Asessmen Kompetensi Minimum dan Survey Karakter di Indonesia.

\section{Teknik Analisis Data}

Metode analisis data menggunakan model Miles dan Huberman yang memuat reduksi data, penyajian data dan verifikasi. Tujuannya adalah untuk mengetahui biografi Ibnu Sina, konsep Asesmen Kompetensi Minimum dan Survei Karakter dalam \#MerdekaBelajar di Indonesia, relevansi antara keduanya, serta kelebihannya dibanding Ujian Sekolah Berstandar Nasional di tahun sebelumnya.

\section{Hasil dan Pembahasan}

\section{Biografi Ibnu Sina}

Nama lengkap Ibnu Sina adalah Abu Ali al-Husein ibn Abdillah ibn Hasan ibn Ali ibn Sina. Ia dikenal sebagai seorang filosof Islam dengan gelar Syaikh ar-Ra'is. Dilahirkan pada tahun 370 H/980 M di desa Ebsyanah (wilayah Bukhara). Wafat tahun 428 H/1036 M di Hamadan. Ia dibesarkan dalam keluarga Syiah, dalam masa usia 10 tahun Ibnu Sina kecil sudah hafiz qur'an, dan dalam usia 16 tahun telah menguasai dengan baik ilmu falsafah, kedokteran, dan ilmu-ilmu agama Islam secara autodidak, bahkan mencapai kedudukan istimewa sehingga banyak orang belajar kepadanya.

Usia 21 tahun, Ibnu Sina mulai menulis gagasannya menjadi beberapa kitab. Hasil karyanya, menurut versi modern, berjumlah 276 buah buku kitab yang mencakup seluruh kajian filosofis, saintifik, kedokteran dan juga kebahasaan. Di Barat dikenal dengan nama Avicena. Hasil karya tulisan Ibnu Sina boleh dikatakan paling bernas dan 
sistematik. Karya tulisnya ada dua versi, yaitu versi bahasa Arab, dan bahasa Persia. ${ }^{4}$ Karya Ibnu Sina sangat banyak dan kelengkapan risalahnya jauh melampaui risalah manapun yang pernah dihasilkan pengarang-pengarang filsafat pertama seperti al-Kindi dan al-Razi. Di antara bukunya yang terkenal adalah: kitab al-Syifa mengenai filsafat, Kitab al-Najat atau Kitab Penyelamat, Kitab al-Qanun fi al-Thibb (Qanon of Medicine) dan Kitab al-Isyarat wa al-tanbihat.al-Isyarat wa al-Tanbihat. ${ }^{5}$

Perez mengemukakan:

"Avicenna's work has an extraordinary richness to study the links between history, art and medicine, propitious for the development of a comprehensive general culture in the future health professionals. An adequate selection of his works allows teacher to link their students with the history of ancient medicine, motivate their classes, exemplify through them the use of medical procedures in which the importance of the doctor-patient relationship prevails and they offer the possibility of consolidating moral values."

Ibnu Sina mempunyai pemikiran yang sangat cemerlang dari berbagai disiplin ilmu pengetahuan. Bahkan dalam perjalanan hidupnya beliau tidak hanya dikenal sebagai seorang ilmuan dengan berbagai hasil karangannya yang telah membuat namanya terkenal di dunia Barat, tetapi beliau juga seorang negarawan yang berkecimpung dalam dunia politik pada zamannya serta sebagai seorang pendidik yang dikagumi. $^{7}$

\section{2. \#MerdekaBelajar di Indonesia}

Sebagaimana dipaparkan sebelumnya, ada empat kebijakan utama \#MerdekaBelajar di Indonesia. Dalam tulisan ini, penulis tidak akan menganalisis keempat kebijakan yang ada, melainkan akan fokus pada kebijakan pertama yakni penggantian Ujian Sekolah Berstandar Nasional (USBN) menjadi Asesmen kompetensi minimum dan Survei karakter. Dalam \#MerdekaBelajar Nadiem Makariem menjelaskan bahwa asesmen kompetensi minimum meliputi dua pokok materi kognitif yaitu literasi dan numerasi.

\footnotetext{
${ }^{4}$ Ummu Kulsum, "Implementasi Pendidikan Akhlak untuk Membentuk Karakter Siswa dalam Perspektif Pemikiran Ibnu Sina," Al-Ulum Jurnal Pemikiran Dan Penelitian Ke Islaman, Vol. 6, No. 2 (2019): 81-90, https://doi.org/10.31102/alulum.6.2.2019.81-90.

${ }^{5}$ Mukhtar Gozali, “Agama dan Filsafat dalam Pemikiran Ibnu Sina," Jaqfi: Jurnal Aqidah Dan Filsafat Islam, Vol. 1, No. 2 (2017): 22-36.

${ }^{6}$ Blasa Melba Menéndez Pérez, et al., "Inclusión de La Historia, Arte y Medicina de Avicena En La Educación Médica,” Edumecentro, Vol. 10, No. 2 (2018): 79-95.

${ }^{7}$ Dosen Fakultas Tarbiyah IAIN Ar-Raniry Banda Aceh, "KONSEP PENDIDIKAN ISLAM," Maidar Darwis XIII, No. 2 (2013): 240-58.
} 
Dewi Ratna Sari \& Betty Mauli Rosa: Asesmen Kompetensi Minimum dan Survey Karakter di Indonesia serta Relevansinya dengan Pemikiran Ibnu Sina

Literasi ini bukan sekedar kemampuan membaca, namun juga merupakan kemampuan dalam menganalisis suatu bacaan dan memahami konsep yang ada di dalamnya. Jadi kemampuan literasi bukan hanya mengukur apakah siswa dapat membaca atau tidak, melainkan juga menilai apakah ia mampu menganalisis dan memahami maksud dari bacaan yang ada. Ma'mun Zahrudin dan kawan-kawan menjelaskan bahwa pemanfaatan hasil Asesmen Kompetensi Minimum dapat menjadi acuan guru untuk menyusun strategi pembelajaran yang efektif dan berkualitas. Hasil Asesmen Kompetensi Minimum juga dapat memberikan gambaran kepada guru mengenai takaran yang tepat untuk setiap teaching at the right level. ${ }^{8}$

Adapun numerasi adalah kemampuan menganalisis menggunakan angka. Numerasi ini bukan hanya mengenai pelajaran Matematika dan literasi tidak pelajaran Bahasa saja, keduanya merupakan penilaian mengenai kemampuan murid-murid dalam menggunakan konsep itu untuk menganalisis sebuah materi. Menurut penelitian Zainal Mustofa, tidak ada perbedaan kemampuan numerasi siswa perempuan dan laki-laki. Beberapa kesulitan yang dialami siswa dalam menyelesaikan soal-soal numerasi mencakup: mengevaluasi nilai pada soal berdasarkan acuan table 63,8\%; menganalisis data table $61,6 \%$; membandingkan dua data dari diagram 54,9\%, dan membandingkan dua grafik dengan fungsi sama 39,6\%. Sehingga penulis menyimpulkan perlu adanya pembelajaran yang melatih terkait soal numerasi agar siswa terbiasa mengerjakan. Terlebih soal ini pada dasarnya hanya membutuhkan kemampuan matematika dasar, namun cukup membuat siswa kesulitan. 9 "Ini berdasarkan kompetensi minimum kompetensi dasar yang dibutuhkan murid-murid untuk bisa belajar apa pun materinya. Ini adalah kompetensi minimum yang dibutuhkan murid untuk bisa belajar apa pun mata pelajarannya," sambung Nadiem. ${ }^{10}$

Mengenai Survei Karakter dalam \#MerdekaBelajar, digunakan untuk mengetahui bagaimana karakter anak di sekolah. Dalam pidatonya Nadiem memberi contoh bahwa survei karakter ini akan menilai bagaimana implementasi gotong royong

\footnotetext{
${ }^{8}$ Shalahudin Ismail and Qiqi Yuliati Zakiah, "Policy Analysis of Implementation of Minimum Competency Assessment As an Effort To Improve Reading” 6356 (2021).

${ }^{9}$ Siti Nurul Hasana, "Pengaruh Penggunaan Multimedia Interaktif terhadap Kemampuan Pemahaman Konsep Matematis Siswa," Jurnal Pendidikan Matematika \& Matematika, Vol. 3, No. 2 (2016): 30-40.

${ }^{10}$ Rahel Narda Chaterine, "Gantikan UN, Apa Itu Asesmen Kompetensi Minimum dan Survei Karakter?,” kompas.com, 2019, https://news.detik.com/berita/d-4818251/gantikan-un-apa-itu-asesmenkompetensi-minimum-dan-survei-karakter.
} 
di sekolah, bagaimana level toleransi yang ada, apakah well-being atau kebahagiaan anak itu sudah mapan dan ada tidaknya bullying. ${ }^{11}$ Survei Karakter ini merupakan salah satu rangkaian dalam pengganti USBN, sehingga bukan merupakan kegiatan tembahan yang bersifat opsional.

Mengenai waktunya Asesmen Kompetensi Minimum dan Survei Karakter, Nadiem berencana melakukannya di tengah jenjang, bukan di akhir jenjang seperti tahun-tahun sebelumnya. Pada tingkat Sekolah Dasar sederajat, akan dilakukan di kelas empat. Sedangkan di Sekolah Menengah Pertama sederajat diadakan pada saat berada di kelas delapan. Hal tersebut agar hasil dari penilaian bisa ditindaklanjuti dengan perbaikan-perbaikan ke depannya.

\section{Relevansi \#MerdekaBelajar di Indonesia dengan Pemikiran Pendidikan} Menurut Ibnu Sina

Ketika membahas mengenai konsep Ujian Sekolah Berstandar Nasional (USBN) yang dalam \#MerdekaBelajar diganti menjadi Asesmen Kompetensi Minimum dan Survei Karakter, ada tiga komponen utama yang dapat ditelaah. Ketiga komponen tersebut yaitu literasi, numerasi dan survei karakter.

Pertama, kemampuan literasi. Literasi dalam \#MerdekaBelajar tidak hanya sebatas mengenai bisa tidaknya siswa membaca huruf-huruf alfabetis dan kalimatkalimat, namun juga mengenai bisa tidaknya siswa memahami dan menganalisis bacaan yang diberikan kepadanya. Penilaian literasi ini berpatokan pada metode asesmen Program for International Student Assesment (PISA). Sebuah survey tiga tahunan yang dilakukan oleh Organisation for Economic Co-operation and Development (OECD) yang menilai kemampuan 600 ribu siswa berusia 15 tahun yang telah memperoleh pengetahuan dan keterampilan utama di 79 negara. Pada asesmen PISA yang dilakukan tahun 2018 hasilnya menurun dibanding tahun 2015, skor Literasi Indonesia turun dari 397 menjadi 371, Matematika dari 386 menjadi 379 dan sains dari 403 menjadi 396. ${ }^{12}$ Hasil dari asesmen PISA tersebut menunjukkan bahwa Indonesia masih perlu melakukan perbaikan dibidang literasi. Mengenai target penilaian pemahaman membaca (literasi) menurut PISA ada beberapa komponen yang dinilai yaitu: (1) teks narasi, (2)

\footnotetext{
${ }^{11}$ Yopi Makdori, "Mengenal Konsep Asesmen Kompetensi Minimum Pengganti Ujian Nasional," m.liputan6.com, 2019, https://m.liputan6.com/news/read/4131579/mengenal-konsep-asesmenkompetensi-minimum-pengganti-ujian-nasional.

${ }^{12}$ Yudono Yanuar, "Inilah Asesmen..."
} 
Dewi Ratna Sari \& Betty Mauli Rosa: Asesmen Kompetensi Minimum dan Survey Karakter di Indonesia serta Relevansinya dengan Pemikiran Ibnu Sina

teks deskripsi, (3) teks eksposisi, (4) teks eksplanasi, (5) teks laporan, (6) teks prosedur, (7) teks pengayaan-mixed genre. ${ }^{13}$

Dalam pandangan pendidikan menurut Ibnu Sina, kemampuan membaca menjadi salah satu komponen yang turut diajarkan dalam pembelajaran. Pelajaran untuk usia 6-14 tahun menurut Ibnu Sina mencakup pelajaran membaca dan menghafal alQur'an, pelajaran agama, pelajaran sya'ir dan pelajaran olah raga. Pelajaran membaca dan menghafal Al Qur'an menurut Ibnu Sina berguna untuk mendukung pelaksanaan Ibadah yang membutuhkan ayat-ayat al-Qur'an dan mendukung keberhasilan dalam mempelajari agama Islam seperti tafsir al-Qur'an, fiqih, tauhid, akhlak dan pelajaran agama lainnya. Fungsi lainnya yaitu untuk mendukung keberhasilan dalam mempelajari Bahasa Arab, karena dengan menguasai al-Qur'an berarti seseorang telah menguasai ribuan kosa kata Bahasa Arab yang juga digunakan dalam al-Qur'an. Jika hal yang bersifat mendasar tersebut telah selesai, barulah dilihat kepada pekerjaan yang diinginkan dan dibimbing ke arah tersebut. Jika anak ingin menjadi juru tulis maka ia diajarkan mengenai surat menyurat, pidato, perdebatan, diskusi dan lain sebagainya. Dari hal tersebut terlihat bahwa penetapan pelajaran membaca al-Qur'an tampaknya bersifat strategis dan mendasar, baik dilihat dari segi pembinaan sebagai pribadi muslim, maupun dari segi pembentukan ilmuan muslim, sebagaimana diperlihatkan oleh Ibnu Sina sendiri. ${ }^{14}$

Pelajaran sya'ir tetap diperlukan pada pembelajaran anak usia 6-14 tahun. Anak perlu menghafal syair-syair yang mengandung nilai-nilai pendidikan karena akan berguna dalam membimbing perilakunya, disamping petunjuk al-Qur'an dan Sunnah. Pelajaran ini dimulai dengan menceritakan syair-syair, hal tersebut karena syair lebih mudah dihafal dan diceritakan serta bait-baitnya lebih pendek. Menurut Ibnu Sina syair ini selain melatih kemampuan berbahasa, juga bisa dimanfaatkan sebagai sarana pendidikan akhlak. Jadi beliau menolak pandangan yang mengatakan bahwa "Seni adalah untuk seni." 15

\footnotetext{
${ }^{13}$ Pusat Asesmen dan Pembelajaran Kemendikbud RI, "Tentang PISA," kemendikbud.go.id, 2019, http://pusmenjar.kemendikbud.go.id/tentang-pisa.

${ }^{14}$ Musdalifah, "Konsep Pendidikan Ibnu Sina tentang Tujuan Pendidikan, Kurikulum, Metode Pembelajaran dan Guru," Jurnal UIN Alaudin, Vol. VIII, No. 2 (2019): 411

${ }^{15}$ Katni, "Hubungan Jiwa-Raga dan Kurikulum Pendidikan Islam menurut Ibnu Sina," Jurnal Kependidikan Islam Al-Idarah, Vol. 6, No 1 (2016): 35-36
} 
Jika dihubungkan kedua hal di atas, baik Asesmen Kompetensi, Asesmen PISA maupun Ibnu Sina menekankan pentingnya kemampuan membaca. Kemampuan membaca tersebut pada ketiganya juga tidak hanya terbatas pada tekstual dalam buku, melainkan juga membahas menganai bagaiamana memahami dan menganalisis suatu bacaan guna difahami maksud yang terkandung di dalamnya.

Kedua, kemampuan numerasi. Fokus asesmen adalah kompetensi berpikir, sehingga hasil pengukuran tidak sekedar mencerminkan prestasi akademik pelajaran Matematika saja. Numerasi justru bisa dan berkembang di berbagai pelajaran lainnya. ${ }^{16}$ Menurut PISA kemampuan Matematika meliputi: (1) pola bilangan, (2) persamaan dan rumus, (3) bentuk aljabar, (4) bilangan cacah dan bilangan bulat, (5) peluang, (6) interpretasi data, dan lain sebagainya. Selain metode asesmen PISA, kemampuan numerasi juga berhubungan dengan Trends in International Mathematics and Science Study (TIMSS). Penilaian TIMSS ini menekankan pada kompetensi Matematika dan Sains. $^{17}$

Dalam khazanah Peradaban Islam, nama Ibnu Sina atau Avicenna juga terkenal dalam pandangannya mengenai Matematika. Dalam tulisan Avicenna: Mathematics and Philosophy dijelaskan like his Greek and Arab prodecessorsss, Avicenna's research in Mathematics concerned the development of methods of exposition, proof procedures and analytical tools. Like them, he occupied himself in clarifying mathematical knowledge and determining its place in the encyclopedia of rational sciences that he wanted to build up. ${ }^{18}$ Di bidang matematika, Ibnu Sina tidak hanya membahas mengenai konsep-konsep mengenai angka, namun juga menghubungkannya dengan filsafat dan kehidupan-kehidupan keseharian.

Di antara ketiga pandangan tersebut ada sebuah kesamaan yaitu pemahaman bahwasannya matematika bukanlah ilmu langit yang jauh dari kehidupan keseharian. Sebaliknya matematika adalah sebuah dasar pemikiran yang bisa membuat seseorang lebih sistematis dalam berfikir dan bertindak. Ada sebuah tulisan menarik yang menjadi pelengkap pandangan mengenai Asesmen Kompetensi, asesmen internasional dan pandangan Ibnu Sina, berupa sebuah paper yang ditulis oleh Annisah Kurniati. Annisah

\footnotetext{
${ }^{16}$ PG Diknas, "Literasi dan Numerasi Adalah Kompetensi yang Bersifat Mendasar," kemdikbud.go.id, 2019.

${ }^{17}$ Yopi Makdori, "Mengenal Konsep..."

${ }^{18}$ Hassan Tahiri, "The Philosophers and Mathematics: Feetschrift for Roshdi Rashed," Springer,
} 2018,249 
Dewi Ratna Sari \& Betty Mauli Rosa: Asesmen Kompetensi Minimum dan Survey Karakter di Indonesia serta Relevansinya dengan Pemikiran Ibnu Sina

menjelaskan bahwa matematika sebaiknya diperkenalkan dan diajarkan kepada anak dengan cara yang menarik dan dengan memadukan dan menyekaraskannya dengan nilai keislaman. Memadukan matematika dengan nilai keislaman akan terbentuk bangsa yang tangguh, berorientasi ilmu pengetahuan dan teknologi yang semuanya dijiwai oleh iman dan takwa kepada Tuhan Yang Maha Esa. ${ }^{19}$

Adapun komponen ketiga yaitu survei karakter. Survei karakter dalam \#MerdekaBelajar mengevaluasi bagaimana karakter siswa dan pembiasaan yang ada di sekolah. Mengenai pentingnya karakter ini telah dipaparkan oleh banyak ahli pendidikan. Ibnu Sina sendiri merupakan salah satu tokoh yang berulang kali menekankan pentingnya perilaku terpuji dalam proses pendidikan.

Ibnu Sina dan tokoh-tokoh pendidikan akhlak menilai bahwa tujuan puncak pendidikan akhlak adalah terbentuknya karakter positif dalam perilaku anak didik. Karakter positif ini tidak lain adalah penjelmaan sifat-sifat mulia Tuhan dalam kehidupan manusia yaitu Asmaul Husna. ${ }^{20}$ Ibnu Sina sangat mementingkan pendidikan akhlak yang mengintegrasikan nilai-nilai idealitas dengan pandangan pragmatis. Hal ini terlihat dari pemikirannya tentang pendidikan anak yang harus dimulai dengan pendidikan al-Qur'an tetapi tidak memberatkan jasmani dan akal pikirannya. Mengembangkan pendidikan akhlak ini bisa dilakukan dengan metode diskusi dan pergaulan anak. Hal tersebut karena akhlak anak sangat dipengaruhi oleh lingkungannya dan pada dasarnya anak adalah peniru yang ulung. Dalam menentukan metode pendidikan, seorang guru perlu untuk memperhatikan psikologi anak. Sedangkan untuk sarana pendidikan akhlak ini salah satunya bisa dilakukan dengan syair yang bertujuan untuk menyampaikan banyak nilai mengenai keutamaan akhlak mulia. ${ }^{21}$

Al-Naqib menyatakan:

"Avicenna sees the aims of education as the overall growth of the individual: physical, mental and moral; followed by preparation of this individual to live in society through a chosen trade according to his aptitudes. Avicenna does not devote his attention to the moral aspect alone, but aims at the formation of a personality complete in body, mind

\footnotetext{
${ }^{19}$ Annisah Kurniati, "Mengenalkan Matematika Terintegrasi Islam Kepada Anak Sejak Dini," Suska Journal of Mathematics Education, No. 1, No. 1 (2015): 1, https://doi.org/10.24014/sjme.v1i1.1326.

${ }^{20}$ Edi Rohendi, "Pendidikan Karakter di Sekolah,” Jurnal Eduhumaniora, Vol. 3 No. 1 (2011): 4, https://doi.org/10.17509/eh.v3i1.2795

${ }^{21}$ Deswita, "Konsep Pemikiran Ibnu Sina tentang Pendidikan Akhlak," Jurnal Ta'dib, Vol. 16. No. 2 (2013): 175
} 
and character. He does not restrict the task of education to creating the complete citizen, but rather sees that education must also prepare him for a profession whereby he can contribute to the social structure, because society, in Avicenna's view, is built entirely on 'co-operation', on the specialization of each individual in a craft or profession and on the mutual exchange of services between its individual. ${ }^{22}$

Pengembangan karakter menurut Ibnu Sina bukanlah sesuatu yang berdiri sendiri. Ia amat berkelindan dengan aspek fisik dan mental dari siswa. Ketiganya saling melengkapi dan membuat pendidikan menjadi salah satu kontributor penting dalam persiapan generasi yang unggul sebagai bekal pengembangan masyarakat yang baik. Melalui proses pendidikan karakter, fisik dan mental inilah seseorang bisa berkolaborasi mengembangkan negaranya melalui potensi yang dimilikinya.

Jika diperhatikan konsep Asesmen kompetensi minimum dan Survei Karakter dalam \#MerdekaBelajar sangat selaras dengan konsep pendidikan menurut Ibnu Sina. Baik dalam kemampuan literasi, numerasi maupun survei karakter mempunyai dasar pemikiran yang sama dengan pandangan Ibnu Sina. Literasi dan numerasi adalah dua komponen yang penting ketika membahas mengenai aspek afektif siswa. Keduanya perlu diajarkan dan dievaluasi dalam setiap proses pendidikan. Pun mengenai karakter dan akhlak mulia yang juga berperan penting untuk membuat seseorang memiliki budi pekerti luhur.

Yang menjadi catatan di sini adalah adanya perbedaan mengenai pengembangan aspek jasmani. Dalam \#MerdekaBelajar, Asesmen Kompetensi Minimum maupun Survei Karakter tidak membahas sama sekali mengenai aspek psikomotor. Literasi dan numerasi masuk ke keterampilan kognitif, sedangkan karakter termasuk keterampilan afektif. Keterampilan psikomotor yang berhubungan dengan pentingnya olah tubuh dan pelajaran yang melibatkan kegiatan fisik sama sekali tidak mendapat porsi pembahasan.

Ketiadaan evaluasi mengenai aspek fisik tersebut berbeda dengan pandangan Ibnu Sina mengenai pendidikan. Ibnu Sina mengatakan bahwa pengaruh jiwa atas tubuh tampak tidak di paksakan: kapanpun pikiran ingin menggerakkan tubuh, maka tubuh akan menaatinya. Berkaca dari realita itulah pengembangan kurikulum pendidikan hendaknya meletakkan pendidikan jiwa menjadi tumpuan, timbulnya hasrat, kemauan, dorongan untuk membaca, belajar, berherak, mengkaji dari faktor intrinsik seharusnya

\footnotetext{
${ }^{22}$ Abdel Rahman al-Naqib, “Avicenna (Ibnu Sina)” International Bureau of Education, Vol. XXIII, No. 1-2, 1993, 51-68
} 
Dewi Ratna Sari \& Betty Mauli Rosa: Asesmen Kompetensi Minimum dan Survey Karakter di Indonesia serta Relevansinya dengan Pemikiran Ibnu Sina

menjadi pehatian pendidik. Ketika jiwa diolah, dibimbing dengan sebaik-baiknya, akan mampu mewujudkan gerak badan secara dinamis. Jika jiwa manusia terkembang dengan baik, maka nilai-nilai positif akan ditransformasikan kepada badan (fisik) dan mengendakikan jiwa-jiwa tumbuhan serta jiwa binatang yang ada dalam tubuh manusia yang lebih sering mendorong ke arah perbuatan negatif. ${ }^{23}$

\section{Kelebihan Asesmen Kompetensi Minimum dan Survei Karakter dibandingkan Ujian Sekolah Berstandar Nasional (USBN)}

Ujian Sekolah Berstandar Nasional (USBN) dan Ujian Nasional (UN) menjadi sebuah kebijakan yang dilematis dan banyak dikritisi. Hal tersebut menyangkut efek negatif berupa belum meratanya kualitas pendidikan di Indonesia, pemborosan anggaran hingga tekanan psikologis. Dalam tesis yang dilakukan oleh Maya Pangastuti tentang Ujian Nasional (UN) sebagai salah satu sumber penyebab kecemasan pada siswa dijelaskan bahwa sebagian siswa menganggap Ujian Nasional adalah proses biasa yang wajib dilalui oleh siswa kelas XII. Namun bagi sebagian lainnya Ujian Nasional bisa menjadi momok yang terus menghantui dan menjadi sebuah mimpi buruk bagi mereka. $^{24}$

Banyaknya dampak negatif dan kurangnya signifikansi terhadap peningkatan kualitas pendidikan membuat kebijakan penghapusan Ujian Nasional maupun Ujian Sekolah Berstandar Nasional menjadi sebuah agenda panjang yang dilakukan sejak beberapa tahun silam. Penghapusan tersebut tidak dilakukan secara serta merta, ada beberapa step yang dilakukan seperti pemberian wewenang kepada daerah untuk menentukan standar, kewenangan sekolah dalam penentuan kelulusan hingga penerapan Penerimaan Peserta Didik Baru (PPDB) zonasi yang membuat nilai UN menjadi tidak terlalu bersifat signifikan.

Peniadaan Ujian Nasional di tingkat Sekolah Menengah Pertama (SMP) sederajat dan Sekolah Dasar (SD) sederajat pada tahun 2020 karena adanya pandemi Covid-19 adalah sebuah momentum pendidikan yang cukup dinantikan. Penerapan kedua konsep \#MerdekaBelajar yang mencanangkan tahun 2020 sebagai tahun terakhir pelaksanaan Ujian Nasional menjadi dimajukan. Hal tersebut memberikan kesempatan

\footnotetext{
${ }^{23}$ Katni, "Hubungan Jiwa-Raga..."

${ }^{24}$ Maya Pangastuti, "Efektifitas Pelatihan Berpikir Positif untuk Menurunkan Kecemasan dalam Menghadapi Ujian Nasional (UN) pada Siswa SMA," Persona: Jurnal Psikologi Indonesia, Vol. 3, No. 01 (2014): 32-41, https://doi.org/10.30996/persona.v3i01.367.
} 
transisi dari USBN dan UN menjadi Asesmen Kompetensi Minimal dan Survei Karakter di tahun setelahnya.

Jika ditelaah dengan seksama, perbedaan yang cukup signifikan dari pelaksanaan Ujian Sekolah Berstandar Nasional (USBN) dengan Asesmen Kompetensi Minimal dan Survei Karakter, justru terletak pada penekanan penilaian mengenai perilaku mulia siswa dan pembiasaan sekolah. Jika sebelumnya USBN lebih menekankan aspek kognitif melalui pelajaran Matematika, Bahasa Indonesia, Ilmu Pengetahuan Alam, Ilmu Pengetahuan Sosial, dan Bahasa Inggris. Pada konsep \#MerdekaBelajar ada penekanan baru mengenai Survei Karakter. Dengan tetap memberikan proporsi afektif melalui asesmen tentang literasi dan numerasi bagi siswa tengah jenjang.

Memetik pengalaman dari negara maju, Djojonegoro berpendapat bahwa dalam menghadapi perdagangan bebas, generasi muda Indonesia perlu mempunyai dua karakteristik kualitas. Pertama, karakteristik kualitas dasar. Karaktersitik kualitas ini meliputi: beriman dan bertaqwa kepada Tuhan Yang Maha Esa, cerdas, berbudi pekerti luhur, berdisiplin, berkepribadian yang mantap dan mandiri, sehat jasmani dan rohani, serta memiliki tanggungjawab kemasyarakatan dan kebangsaan. Kedua, karakteristik kualitas instrumental. Kualitas ini harus selalu diperbarui sesuai dengan perkembangan dan perubahan yang ada. Hal tersebut meliputi: kemampuan produktif, kemampuan berkomunikasi, kemampuan sumber daya, kemampuan menggunakan ilmu dan teknologi serta kemampuan memecahkan masalah. ${ }^{25}$ Pandangan ini menunjukkan bahwasannya Asesmen Kompetensi Minimum dan Survei Karakter melatih dua hal tersebut sekaligus. Menekankan pentingnya kualitas dasar melalui survey karakter, sekaligus kualitas instrumental melalui literasi dan numerasi.

Adanya penggantian Ujian Sekolah Berstandar Nasional menjadi Asesmen Kompetensi Minimum dan Survei Karakter ini menjadi sebuah momen untuk melakukan refleksi dan mengajak untuk mengecek kembali tujuan pendidikan di Indonesia. Dalam pidato, pernyataan maupun dokumentasi terkait kebijakan \#MerdekaBelajar menurut Nadiem Makarim ini, tidak ada perubahan terkait esensi tujuan pendidikan di Indonesia. Landasan yuridis terkait tujuan pendidikan masih mengacu pada Undang-undang Republik Indonesia Nomor 20 Tahun 2003 tentang

\footnotetext{
${ }^{25}$ Suwandi, "Evaluasi Pelaksanaan Ujian Akhir Sekolah Berstandar Nasional (UASBN)" Jurnal Pendidikan Teknologi dan Kejuruan, Vol. 21, No. 3 (2013): 227-237.
} 
Dewi Ratna Sari \& Betty Mauli Rosa: Asesmen Kompetensi Minimum dan Survey Karakter di Indonesia serta Relevansinya dengan Pemikiran Ibnu Sina

Sistem Pendidikan Nasional. Dalam Undang-undang tersebut dijelaskan bahwa pendidikan adalah usaha sadar dan terencana untuk mewujudkan suasana belajar dan proses pembelajaran agar peserta didik secara aktif mengembangkan potensi dirinya untuk memiliki kekuatan spiritual keagamaan, pengendalian diri, kepribadan, kecerdasan, akhlak mulia, serta keterampilan yang diperlukan dirinya, masyarakat, bangsa dan negara. ${ }^{26}$ Lebih lanjut dalam pasal 3 dijelaskan bahwa pendidikan bertujuan untuk berkembangnya potensi peserta didik agar menjadi manusia yang beriman dan bertakwa kepada Tuhan Yang Maha Esa, berakhlak mulia, sehat, berilmu, cakap, kreatif, mandiri, dan menjadi warga negara yang demokratis serta bertanggungjawab. ${ }^{27}$

Sistem pendidikan nasional sebenarnya tidak menominasi sistem pendidikan Islam Indonesia, dan makna manusia seutuhnya dalam tujuan pendidikan nasional sebagai proses kemanusiaan yang bertindak dalam logika berfikir sebagai makluk yang berakal dan berbudi, juga sebagai proses pemanusiaan yang mampu menjalankan tugas pokok dan fungsi secara penuh pemegang mandat ilahiah yang merujuk pada hubungan dengan Tuhannya berikut perilaku yang dikehendaki di dalamnya dan mandat kultural yang mengandung makna sebagai insan berbudaya. Pendidikan Islam merupakan bagian yang integral dari Sistem Pendidikan Nasional. Sebagai bagian dari sistem pendidikan nasional, pendidikan Islam mendapat legitimasi untuk eksis dan mendapatkan tempat dan berkembang di Indonesia untuk memenuhi kebutuhan pendidikan bagi masyarakat Islam sebagai warga mayoritas.

Dua hal ini jika dihubungkan dengan tujuan pendidikan menurut Ibnu Sina akan sangat relevan. Ibnu Sina mengatakan bahwa tujuan pendidikan itu harus diarahkan pada pengembangan seluruh potensi ke arah perkembangan yang sempurna, yaitu perkembangan fisik, intelektual dan budi pekerti dalam rangka menciptakan insan kamil. Perkembangan fisik berkelindan dengan terma sehat. Intelektual berhubungan dengan berilmu, cakap dan kreatif. Sedangkan budi pekerti terimplementasi dalam bentuk beriman dan bertakwa kepada Tuhan Yang Maha Esa, berakhlak mulia dan menjadi warga negara yang demokratis serta bertanggungjawab.

Wacana pengubahan format Ujian Sekolah Berstandar Nasional (USBN) dan Ujian Nasional (UN) menjadi Asessmen Kompetensi Minimum dan Survey Karakter

\footnotetext{
${ }^{26}$ Undang-undang Republik Indonesia Nomor 20 Tahun 2003 tentang Sistem Pendidikan Nasional, hlm. 3

${ }^{27}$ Ibid., 5
} 
dalam \#MerdekaBelajar juga menekankan proporsi tersebut. Adanya kombinasi penilaian literasi, numerasi dan karakter mengindikasikan bahwa penilaian tentang akhlak mulia turut menjadi perhatian di masa sekarang. Terkait penilaian karakter ini yang ada beberapa hal yang bisa dinilai misalnya sikap pembelajar, gotong royong, kebhinekaan dan perundungan. Sesuatu yang secara praksis maupun konseptual sangat relevan dengan tujuan pendidikan Indonesia yang dipaparkan dalam Undang-undang.

\section{Simpulan}

\#MerdekaBelajar adalah gagasan yang ditawarkan oleh Menteri Pendidikan dan Kebudayaan (Mendikbud) Nadiem Makarim. Ada empat pokok kebijakan pendidikan yang dibahas meliputi: 1) Ujian Sekolah Berstandar Nasional (USBN). 2) Ujian Nasional (UN). 3) Rencana Pelaksanaan Pembelajaran (RPP). 4) Peraturan Penerimaan Peserta Didik Baru (PPDB) Zonasi. Keempat kebijakan tersebut merupakan sebuah upaya yang dilakukan oleh pemangku kebijakan di bidang pendidikan guna menghadapi perkembangan yang ada.

Meski lahir pada masa yang berbeda konsep \#MerdekaBelajar yang dicanangkan oleh Nadiem Makarim sangat sesuai dengan konsep yang pernah dipaparkan oleh Ibnu Sina mengenai pendidikan. Hal tersebut terlihat dari Asesmen kompetensi minimum dan Survei Karakter yang merupakan pengganti Ujian Sekolah Berstandar Nasional (USBN). Ada tiga kompetensi yang dinilai yakni literasi, numerasi dan karakter. Ketiganya sangat selaras dengan pandangan Ibnu Sina mengenai pendidikan. Perbedaannya terletak pada ketiadaan penilaian mengenai aspek jasmani, yang dinilai Ibnu Sina termasuk penting untuk dilakukan.

Terkait Asesmen Kompetensi Minimum dan Survei Karakter sebagai pengganti Ujian Sekolah Berstandar Nasional (USBN) memang memiliki kelebihan jika dihubungkan dengan perkembangan zaman. Hal tersebut terlihat dari pentingnya kualitas dasar melalui survey karakter, sekaligus kualitas instrumental melalui literasi dan numerasi. Dua kualitas dasar yang penting bagi pemuda-pemudi Indonesia di masa depan. 
Dewi Ratna Sari \& Betty Mauli Rosa: Asesmen Kompetensi Minimum dan Survey Karakter di Indonesia serta Relevansinya dengan Pemikiran Ibnu Sina

\section{E. Daftar Pustaka}

Al-Naqib, Abdel Rahman. "Avicenna (Ibnu Sina).” International Bureau of Education, Vol. XXIII, No. 1-2, 1993, 51-68

Chaterine, Rahel Narda. "Gantikan UN, Apa Itu Asesmen Kompetensi Minimum dan Survei Karakter?.” kompas.com, 2019. https://news.detik.com/berita/d4818251/gantikan-un-apa-itu-asesmen-kompetensi-minimum-dan-surveikarakter.

Deswita. "Konsep Pemikiran Ibnu Sina tentang Pendidikan Akhlak." Jurnal Ta'dib, Vol. 16. No. 2 (2013): 175

Dosen Fakultas Tarbiyah IAIN Ar-Raniry Banda Aceh, "KONSEP PENDIDIKAN ISLAM." Maidar Darwis XIII, No. 2 (2013): 240-58.

Gozali, Mukhtar. "Agama dan Filsafat dalam Pemikiran Ibnu Sina." Jaqfi: Jurnal Aqidah Dan Filsafat Islam, Vol. 1, No. 2 (2017): 22-36.

Hasana, Siti Nurul. "Pengaruh Penggunaan Multimedia Interaktif terhadap Kemampuan Pemahaman Konsep Matematis Siswa." Jurnal Pendidikan Matematika \& Matematika, Vol. 3, No. 2 (2016): 30-40.

Ismail, Shalahudin and Qiqi Yuliati Zakiah. "Policy Analysis of Implementation of Minimum Competency Assessment As an Effort To Improve Reading." 6356 (2021).

Katni. "Hubungan Jiwa-Raga dan Kurikulum Pendidikan Islam Menurut Ibnu Sina." AlIdarah: Jurnal Kependidikan Islam, Vol. 6, No 1 (2016): 18-42. https://doi.org/10.24042/alidarah.v6i1.788

Kulsum, Ummu. "Implementasi Pendidikan Akhlak untuk Membentuk Karakter Siswa dalam Perspektif Pemikiran Ibnu Sina." Al-Ulum Jurnal Pemikiran Dan Penelitian Ke Islaman, Vol. 6, No. 2 (2019): 81-90, https://doi.org/10.31102/alulum.6.2.2019.81-90.

Kurniati, Annisah. "Mengenalkan Matematika Terintegrasi Islam Kepada Anak Sejak Dini." Suska Journal of Mathematics Education, No. 1, No. 1 (2015): 1, https://doi.org/10.24014/sjme.v1i1.1326.

Makdori, Yopi. "Mengenal Konsep Asesmen Kompetensi Minimum Pengganti Ujian Nasional." m.liputan6.com, 2019. https://m.liputan6.com/news/read/4131579/ mengenal-konsep-asesmen-kompetensi-minimum-pengganti-ujian-nasional.

Musdalifah. "Konsep Pendidikan Ibnu Sina tentang Tujuan Pendidikan, Kurikulum, Metode Pembelajaran dan Guru." Jurnal UIN Alaudin, Vol. VIII, No. 2 (2019): 411

Muta'ali, Jihad Ahmad. "Opini Masyarakat Tentang Asesmen Nasional sebagai Penganti Ujian Nasional." Journal of Chemical Information and Modeling, Vol. 53, No. 9 (2020): 1689-99.

Pangastuti, Maya. "Efektifitas Pelatihan Berpikir Positif untuk Menurunkan Kecemasan dalam Menghadapi Ujian Nasional (UN) pada Siswa SMA.” Persona: Jurnal Psikologi Indonesia, Vol. 3, No. $01 \quad$ (2014): $32-41$, https://doi.org/10.30996/persona.v3i01.367. 
Pérez, Blasa Melba Menéndez, et al. "Inclusión de La Historia, Arte y Medicina de Avicena En La Educación Médica.” Edumecentro, Vol. 10, No. 2 (2018): 79-95.

PG Diknas. "Literasi dan Numerasi Adalah Kompetensi yang Bersifat Mendasar." kemdikbud.go.id, 2019.

Prodjo, Wahyu Adityo. "Mendikbud Nadiem Hapus UN Lewat Merdeka Belajar, Ini Penggantinya." kompas.com, 2019. https://edukasi.kompas.com/read/2019/12/11/13264851/mendikbud-nadiemhapus-un-lewat-merdeka-belajar-ini-penggantinya.

Pusat Asesmen dan Pembelajaran Kemendikbud RI. "Tentang PISA." kemendikbud.go.id, 2019, http://pusmenjar.kemendikbud.go.id/tentang-pisa.

Rohendi, Edi. "Pendidikan Karakter di Sekolah." Jurnal Eduhumaniora, Vol. 3 No. 1 (2011): 4, https://doi.org/10.17509/eh.v3i1.2795

Suwandi. "Evaluasi Pelaksanaan Ujian Akhir Sekolah Berstandar Nasional (UASBN)." Jurnal Pendidikan Teknologi dan Kejuruan, Vol. 21, No. 3 (2013): 227-237.

Tahiri, Hassan. "The Philosophers and Mathematics: Feetschrift for Roshdi Rashed." Springer, 2018, 249

Undang-undang Republik Indonesia Nomor 20 Tahun 2003 tentang Sistem Pendidikan Nasional

Yanuar,Yudono. "Inilah Asesmen Kompetensi Minimum Pengganti Ujian Nasional." tempo.co, 2019, https://tekno.tempo.co/read/1284119/inilah-asesmenkompetensi-minimum-pengganti-ujian-nasional/full\&view=ok. 